\title{
Sérum lactescent aux urgences
}

\section{Lactescent-looking serum at the emergency department}

\section{A.S. Perick - F. Thys $\cdot$ F. Verschuren}

Reçu le 24 juillet 2011 ; accepté le 27 juillet 2011

(C) SFMU et Springer-Verlag France 2011

Une patiente de 32 ans se présente au service des urgences suite à l'apparition d'une douleur abdominale aiguë accompagnée de vomissements. Elle n'a pas d'antécédents particuliers. Tandis que le médecin urgentiste confirme une défense abdominale en région méso- et hypogastrique, l'infirmière lui signale un aspect lactescent du prélèvement sanguin réalisé (Fig. 1). Ce sérum à l'aspect lactescent apporte une forte raison de suspecter une pancréatite aiguë, qui sera confirmée tant biologiquement que radiologiquement. Cet aspect particulier du sérum justifie le dosage de triglycérides en urgence, dont la valeur sera de $8100 \mathrm{mg} / \mathrm{dl}$ (92 mmol/l). Une hypertriglycéridémie primitive se caractérise par des valeurs supérieures à $1000 \mathrm{mg} / \mathrm{dl}$ (> $11 \mathrm{mmol} / \mathrm{l})$. De telles valeurs peuvent stimuler puis amplifier une réaction ischémique et inflammatoire du pancréas [1]. En dehors du traitement classique de la pancréatite aiguë administré aux urgences, la thérapie doit viser à abaisser rapidement les concentrations de triglycérides, par un jeûne, de l'héparine, de l'insuline ainsi qu'une plasmaphérèse dans les cas les plus compliqués. Un sérum lactescent dans le contexte d'une douleur abdominale aiguë doit donc guider le clinicien vers un diagnostic de pancréatite aiguë, et faire proposer le dosage en urgence des triglycérides en vue de l'instauration éventuelle d'une thérapeutique spécifique.

\section{Référence}

1. Tsuang W, Navaneethan U, Ruiz L, et al (2009) Hypertriglyceridemic pancreatitis: presentation and management. Am J Gastroenterol 104(4):984-91

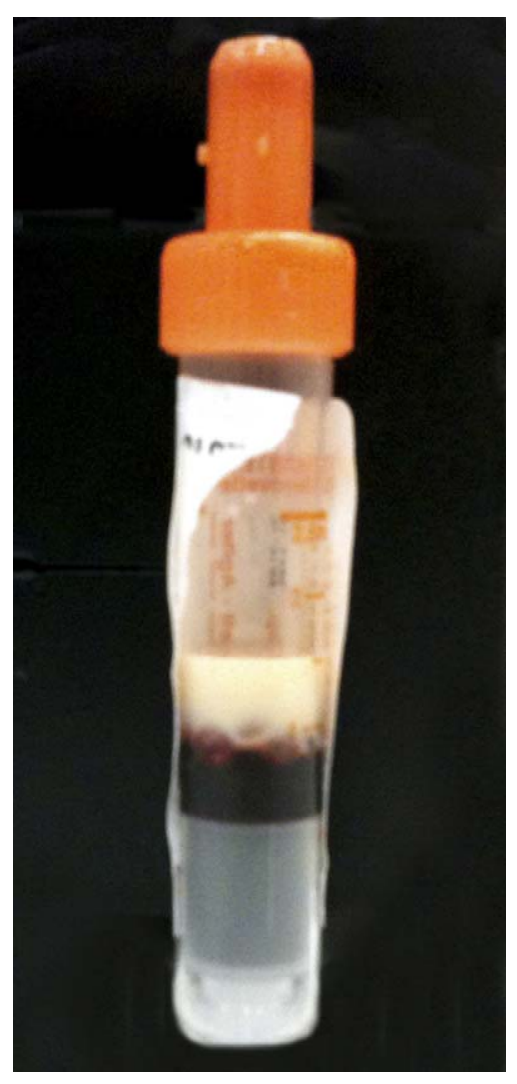

Fig. 1 Sérum lactescent après centrifugation, chez une patiente présentant une pancréatite aiguë secondaire à une hypertriglycéridémie

\footnotetext{
A.S. Perick $\cdot$ F. Thys $\cdot$ F. Verschuren $(\bowtie)$

Département de médecine aiguë,

UCL cliniques université Saint-Luc,

B-1200 Bruxelles, Belgique

e-mail : Franck.verschuren@uclouvain.be
} 